\title{
Produção da cebola em função da densidade de plantas
}

\author{
Francisco Olmar G de Menezes Júnior; João Vieira Neto
}

Epagri-EE de Ituporanga, C. Postal 121,88400-000 Ituporanga-SC; franciscomenezes@epagri.sc.gov.br; joaoneto@epagri.sc.gov.br

\section{RESUMO}

O estabelecimento da densidade ideal de plantas por hectare segundo a espécie, cultivar, sistema e região de cultivo é de extrema importância para o sucesso econômico da atividade olerícola. O objetivo deste trabalho foi avaliar os efeitos de cinco densidades de plantas $\left(200,250,300,400\right.$ e 600 mil plantas ha $\left.{ }^{-1}\right)$, em diferentes arranjos espaciais, sobre a produção e qualidade de bulbos, e rentabilidade da cultivar de cebola Empasc 355-Juporanga. O experimento foi realizado na Epagri, EE de Ituporanga, de maio a dezembro de 2010. Foram avaliados o ciclo, a produtividade, perda pós-colheita, a rentabilidade da cultura e características biométricas das plantas. O delineamento experimental utilizado foi de blocos ao acaso, em parcela subdividida no tempo, com quatro repetições. Observou-se que o aumento da densidade de plantas não influenciou a produtividade comercial $\left(36,19 \mathrm{t} \mathrm{ha}^{-1}\right)$ e de bulbos das classes 3 e superiores $\left(31,91\right.$ t ha $\left.^{-1}\right)$, bem como na conservação de bulbos após três meses de armazenamento. Contudo, resultou na aceleração do ciclo da cultivar (em aproximadamente uma semana), na redução do diâmetro e massa fresca dos bulbos, no aumento da produtividade total (de 33,58 para $41,92 \mathrm{t} \mathrm{ha}^{-1}$ ) e de bulbos da classe 2 (com o aumento da densidade

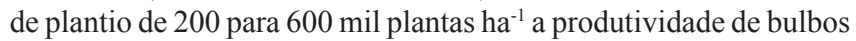
da classe 2 passou de 0,28 para 10,92 $\mathrm{t} \mathrm{ha}^{-1}$ ). A obtenção de bulbos de maior qualidade (classe 3 ) é obtida quando do uso de densidades populacionais entre 400.000 e 600.000 plantas ha $^{-1}$. Considerando os custos de mão de obra, nas operações de transplante e colheita, e preços pagos ao produtor, a análise custo/benefício indica um acréscimo de $\mathrm{R} \$ 682,45 \mathrm{ha}^{-1}$ na rentabilidade com o uso de densidades populacionais de 600 mil plantas ha-1.

Palavras-chave: Allium cepa, arranjos de plantas, conservação póscolheita, rentabilidade.

\begin{abstract}
Onion production depending on planting density

The determination of the optimal density of plants per hectare considering species, cultivar, growing region and the system adopted is very important for the economic viability of the vegetable crop activity. We evaluated the effects of five plant densities (200, 250, 300, 400 and 600 thousand plants/ha) in different spatial arrangements on the yield and quality of bulbs of onion cultivar Empasc 355-Juporanga. The experiment was carried out at Epagri, Santa Catarina state, Brazil, from May to December 2010. We evaluated the cycle, productivity, post-harvest losses, crop return and biometric characteristics of the plants. The experimental design was randomized blocks, "split plot" in time, with four replications. The increasing of planting densities had no effect on commercial productivity of bulbs $\left(36.19 \mathrm{t} \mathrm{ha}^{-1}\right)$ and on the productivity of bulbs in classes 3 and above $\left(31.91 \mathrm{t} \mathrm{ha}^{-1}\right)$ and in the conservation of bulbs after three months of storage. However, this procedure resulted in the acceleration of the cycle of the cultivar (about seven days), reduction of the diameter and fresh mass of bulbs and increase of the total yield of bulbs (from 33.58 to $41.92 \mathrm{t} \mathrm{ha}^{-1}$ ) and yield of bulbs of class 2 (from 0.28 to $10.92 \mathrm{t} \mathrm{ha}^{-1}$ ). The achievement of higher quality bulbs (class 3 ) is obtained when using densities between 400,000 and 600,000 plants ha ${ }^{-1}$. Considering the costs of labor, in transplant and harvest operations, and prices paid to growers, the cost/benefit analysis indicates an increase of US\$ 426.53 per hectare in the profitability by using densities of 600,000 plants ha $^{-1}$.
\end{abstract}

Keywords: Allium cepa, plant arrangement, postharvest, profitability.

(Recebido para publicação em 24 de junho de 2011; aceito em 9 de novembro de 2012) (Received on June 24, 2011; accepted on November 9, 2012)

$\mathrm{O}$ desempenho agronômico de uma dada espécie está relacionado tanto à sua adaptação local quanto às práticas de manejo fitotécnico. Na cultura da cebola a escolha do genótipo está primariamente condicionada aos requerimentos de fotoperíodo e temperatura, típicos de cada cultivar (e característicos a cada região produtora), necessários ao processo de bulbificação. Por sua vez, busca-se através das práticas de manejo propiciar condições que auxiliem o genótipo adotado a expressar seu máximo potencial de forma a combinar características produtivas adequadas ao comércio que se traduzam em rentabilidade para o agricultor.

Dentre os fatores de manejo fitotéc- nico determinantes à produção comercial de bulbos, destaca-se o estabelecimento da população ideal de plantas por hectare para cada cultivar e sistema de cultivo (Baier et al., 2009).

No estado de São Paulo, os produtores rurais têm adensado suas lavouras e buscado novas distribuições espaciais de plantas com vistas à obtenção de bulbos uniformes de tamanho médio (50 a 70 $\mathrm{mm}$ ) considerados de melhor padrão de qualidade (Cecílio Filho et al., 2006; May et al., 2007).

Segundo Brewster (1994), para a obtenção de bulbos de cebola entre 50 e $70 \mathrm{~mm}$ de diâmetro transversal a população de plantas deve variar entre 500 e
1.000 mil plantas ha ${ }^{-1}$, enquanto que para a produção de bulbos maiores deve-se trabalhar com uma população entre 250 e 500 mil plantas ha ${ }^{-1}$. Contudo, de acordo com Ferreira (2000), algumas cultivares de cebola permitem o aumento da densidade de plantio, enquanto em outras, tal procedimento aumenta a produção de bulbos de menor tamanho.

Na região do Alto Vale do Itajaí-SC, para cultivares de cebola recomendadas, têm sido utilizadas populações que variam de 266 a 400 mil plantas ha ${ }^{-1}$, sendo normalmente indicadas densidades populacionais de 333 mil plantas ha ${ }^{-1}$, considerada a que possibilita a colheita de bulbos de tamanho médio (50 a $70 \mathrm{~mm}$ ) e 
alta produtividade (Epagri, 2000).

Pesquisas realizadas por Galmarini \& Gaspera (1995), Stoffella (1996), Boff et al. (1998) e Dellacecca \& Lovato (2000) evidenciam correlação positiva entre a população de plantas e produtividade total de bulbos, contudo, há uma redução do tamanho, diâmetro transversal e massa média dos bulbos. Nessa condição, o pseudocaule tende a ser mais fino e arredondado (Melo et al., 1988). Por sua vez, quando a população de plantas é demasiadamente baixa os bulbos tendem a ser chatos e o pseudocaule grosso (Lopes, 1987).

O ciclo da cultura também pode ser afetado pelo aumento da população de plantas. Dependendo da cultivar utilizada, pode-se acelerar (Cardoso \& Costa, 1999, citado por Baier et al., 2009) ou retardar (Lopes, 1987) progressivamente a maturação dos bulbos.

Para Rabinowitch \& Brewster (1990), em plantas conduzidas sob condições ideais, o aumento da população de plantas irá conduzir a aceleração do processo de bulbificação.

De acordo com os cebolicultores do Alto Vale do Itajaí, a cultivar Empasc 355-Juporanga possui adaptação ao cultivo em maior densidade populacional com significativo aumento de produtividade comercial. Contudo, desde o seu lançamento como cultivar em 1989 (Gandin et al., 1989), poucas informações se encontram disponíveis sobre o comportamento produtivo sob tal condição (Gandin et al., 1994).

O objetivo deste estudo foi avaliar o efeito de diferentes densidades e arranjos espaciais de plantas no ciclo, na produtividade, na perda de massa fresca dos bulbos na pós-colheita e qualidade de cebola da cultivar Empasc 355-Juporanga, bem como no retorno econômico nas condições do Alto Vale do Itajaí.

\section{MATERIAL E MÉTODOS}

O experimento foi conduzido na Epagri, EE de Ituporanga $\left(27^{\circ} 38^{\prime} \mathrm{S}\right.$, $49^{\circ} 60^{\prime} \mathrm{O}$, altitude $475 \mathrm{~m}$ ). Segundo a classificação de Köeppen, o clima local é do tipo Cfa. Utilizou-se a cultivar Empasc 355-Juporanga na safra de 2010. A cultivar possui como principais características ciclo vegetativo médio (de 180 a 210 dias), bulbos de cor ama- relo e amarelo intenso e forma globular e bojuda, estalo (tombamento natural) acima de $80 \%$, perda de massa fresca após três meses de armazenamento de $19,32 \%$ e produtividade média de 33,38 t ha-1 (Gandin et al., 1989; Gandin et al., 1994). A semeadura, o transplante e a colheita foram realizados em $06 / 05$, 27/07 e 15/12/2010, respectivamente.

As mudas foram produzidas de acordo com as indicações técnicas da Epagri (2000). No momento do transplante as mudas apresentavam, em média, 4 folhas emitidas, diâmetro do pseudocaule de $5,83 \mathrm{~mm}$, diâmetro do pseudobulbo de $6,63 \mathrm{~mm}$, altura de $32,13 \mathrm{~cm}$, massa fresca de 4,24 g e massa seca de 0,47 $\mathrm{g}$.

Utilizou-se o delineamento experimental de blocos ao acaso, em parcela subdividida no tempo, com quatro repetições. A área total de cada parcela experimental foi de 9,6 $\mathrm{m}^{2}(3,0 \times 3,2 \mathrm{~m})$, tendo como área útil $6,9 \mathrm{~m}^{2}$.

Foram avaliadas cinco densidades de plantas $(200,250,300,400$ e 600 mil plantas ha-1) sob diferentes arranjos espaciais, na parcela, sendo mantido o espaçamento entre plantas na linha em $10 \mathrm{~cm}$ para todos os tratamentos. Nas densidades de 200 e 250 mil plantas $\mathrm{ha}^{-1}$ as mudas foram transplantadas em linhas simples no espaçamento de 50 e $40 \mathrm{~cm}$ entre linhas, respectivamente. $\mathrm{Na}$ densidade de 300 mil plantas ha ${ }^{-1}$, as mudas foram transplantadas em uma linha dupla (10 x $10 \mathrm{~cm}$ entre linhas) e uma linha simples distanciada em 40 $\mathrm{cm}$ de cada uma das linhas duplas. Por sua vez, na densidade de 400 mil plantas $\mathrm{ha}^{1}$, as mudas foram transplantadas em linhas duplas $(10 \times 10 \mathrm{~cm}$ entre linhas $)$ distanciadas umas das outras em $40 \mathrm{~cm}$. Por fim, na densidade de plantio de 600 mil plantas ha-1 as mudas foram transplantadas em linhas triplas $(10 \times 10 \mathrm{x}$ $10 \mathrm{~cm}$ entre linhas) distanciadas em 30 $\mathrm{cm}$ umas das outras.

Após o transplante, em $3,9 \mathrm{~m}^{2}$ da área útil, realizou-se medições periódicas, correspondentes às subparcelas, do número de folhas emitidas, diâmetro médio do pseudocaule, diâmetro máximo do pseudobulbo ou bulbo, altura (do colo até o ápice da maior folha), massa fresca e seca total das plantas aos 30, 50, 70, 90, 108, 127 e 141 dias após o transplante (DAT) coletadas, em sequência, em uma linha transversal de cada uma das parcelas experimentais. Aos 90, 108, 127 e 141 DAT foram mensuradas as massas fresca e seca de bulbos, folhas e total.

A análise do solo foi realizada em laboratório da EE de Ituporanga. As análises foram realizadas em amostras retiradas das profundidades de 0-10 e $10-20 \mathrm{~cm}$, as quais, respectivamente, apresentaram os seguintes resultados: argila $=480$ e $560 \mathrm{~g} \mathrm{dm}^{-3} ; \mathrm{pH}\left(\mathrm{H}_{2} \mathrm{O}\right)=$ 5,8 e 5,4; $\mathrm{pH}$ (índice SMP) $=6,0$ e 5,8; M.O. $=38$ e $26 \mathrm{~g} \mathrm{dm}^{-3}$; P (Mehlich 1$)=$ 37,0 e $6,0 \mathrm{mg} \mathrm{dm}^{-3} ; \mathrm{H}+\mathrm{Al}=44$ e 56 $\mathrm{mmol}_{\mathrm{c}} \mathrm{dm}^{-3} ; \mathrm{K}=7,9$ e 3,5 mmolc $\mathrm{dm}^{-3}$; CTC $\left(\mathrm{pH}_{7,0}\right)=172$ e $156 \mathrm{mmol}_{\mathrm{c}} \mathrm{dm}^{-3}$; $\mathrm{Al}=0,0$ e $1,0 \mathrm{mmol}_{\mathrm{c}} \mathrm{dm}^{-3} ; \mathrm{Ca}=78$ e 63 $\mathrm{mmol}_{\mathrm{c}} \mathrm{dm}^{-3} ; \mathrm{Mg}=42$ e $35 \mathrm{mmol}_{\mathrm{c}} \mathrm{dm}^{-3}$.

A área experimental foi cultivada anteriormente com milheto, o qual foi incorporado ao solo por aração antes da calagem. A calagem foi realizada em 21/06/2010 com calcário, com 40\% de $\mathrm{CaO}, 5 \%$ de $\mathrm{MgO}$ e $\mathrm{PRNT}=66,5 \%$, na dose de 3,5 t ha ${ }^{-1}$, objetivando-se elevar o pH para 6,0. O calcário foi distribuído na superfície do solo e incorporado através de gradagem. Procedeu-se a adubação de base, em 26/07/2010, com $140 \mathrm{~kg}$ $\mathrm{ha}^{-1}$ de $\mathrm{P}_{2} \mathrm{O}_{5}$ e $60 \mathrm{~kg} \mathrm{ha}^{-1}$ de $\mathrm{K}_{2} \mathrm{O}$ na forma de superfosfato simples e sulfato de potássio, respectivamente. A adubação nitrogenada correspondeu à dose de 75 $\mathrm{kg} \mathrm{ha}^{-1}$ de $\mathrm{N}$, aplicado na forma de uréia no plantio e em três coberturas $(45,65$ e 90 DAT) correspondendo a 20, 35, 25 e $20 \%$ da dose total, respectivamente. Os fertilizantes minerais aplicados na base foram distribuídos a lanço e incorporados ao solo manualmente com enxada. As quantidades do corretivo e dos fertilizantes minerais seguiram as recomendações da CQFSRS/SC (Comissão de Química e Fertilidade do Solo, 2004).

O solo foi preparado pelo sistema convencional,semelhante ao adotado pelos agricultores da região, constando de uma aração na profundidade de $20 \mathrm{~cm}$ e uma operação com enxada rotativa. $\mathrm{O}$ manejo fitossanitário foi realizado, conforme a necessidade, com os produtos químicos registrados para a cultura.

A colheita foi realizada quando as plantas apresentavam mais de 70\% de tombamento. Após a cura a campo, aos 
sete dias após a colheita das plantas, realizou-se a retirada de raízes e o "destalamento" das plantas de forma a deixar uma porção de $1 \mathrm{~cm}$ do pseudocaule. A classificação dos bulbos foi feita com base em seu diâmetro transversal (DT), conforme as normas estabelecidas para a cultura (Brasil, 1995). Para cada classe, mediu-se a massa fresca de bulbos. Determinou-se então a produtividade total (PT), comercial (PC), classe 2 (C2), classe $3(\mathrm{C} 3)$ e da classe 3 e superiores $(\mathrm{C} 3+)$. Para tal foram colhidas plantas em 3,0 $\mathrm{m}^{2}$ da área útil total de cada parcela experimental. Após a classificação e pesagem, os bulbos foram ensacados e levados ao estaleiro onde permaneceram por três meses. Findo esse período realizou-se a análise de conservação pós-colheita, a qual considerou percentagem da perda de massa fresca inicial dos bulbos.

Durante o experimento registraram-se na Estação Meteorológica da EE de Ituporanga valores médios de $83 \%$ de umidade relativa do ar, $1.063 \mathrm{~mm}$ de precipitação, e $11,0,16,0$ e $20,2^{\circ} \mathrm{C}$ de temperatura mínima, média e máxima do ar, respectivamente.

A avaliação do retorno econômico foi realizada com base nos custos de produção e remuneração paga ao agricultor (considerando a média das últimas cinco safras agrícolas do estado catarinense) e na classificação adotada na região do Alto Vale do Itajaí-SC pelos chamados "cerealistas", responsáveis pela compra dos produtores e comercialização da cebola produzida no estado. Esses remuneram o produtor com base em apenas dois parâmetros, sendo considerados comerciais os bulbos das classes 2 (DT de 35 a $50 \mathrm{~mm}$ ) e da classe 3 e superiores (DT acima de $50 \mathrm{~mm}$ ). Para todos os efeitos, bulbos da classe 2 recebem a metade da remuneração do que aqueles correspondentes às demais classes superiores, enquanto bulbos classificados nas classes 0 e 1 (DT abaixo de $35 \mathrm{~mm}$ ) são descartados.

Os dados foram submetidos à análise de variância pelo teste $\mathrm{F}$ através dos programas estatísticos SANEST (Zonta \& Machado, 1984) e NTIA (Embrapa, 1997). Alcançando significância $(\mathrm{p}<0,05)$ as variáveis foram analisadas através de regressão, para efeito simples do fator densidade, e de superfície de resposta, para a interação entre densidade de plantas e épocas de amostragens.

\section{RESULTADOS E DISCUSSÃO}

A análise de variância revelou efeito simples da população de plantas e DAT (dias após o transplante) para o diâmetro do pseudocaule (DP), altura das plantas (AP) e massa fresca dos bulbos (MFB), enquanto que para as demais variáveis agronômicas houve interação entre os dois fatores.

$\mathrm{O}$ aumento da população de plantas reduziu, de forma linear, o DP $\left(\mathrm{y}_{\mathrm{DP}}=\right.$ 16,404321- 0,0000083x, $\mathrm{R}^{2}=0,99$ ). por Melo et al. (1988) que ao elevar a densidade de plantas observou a redução do diâmetro do pseudocaule. Do ponto de vista fitotécnico, o desenvolvimento de plantas com maior DP é indesejável Este resultado assemelha-se ao obtido

por dificultar o tombamento natural das plantas, principal indicativo do momento de colheita. No aspecto fitossanitário, essa condição favorece o ataque de doenças, em especial bacterioses, devido ao acúmulo de água entre as bases das folhas tubulares formadoras do pseudocaule.

Por sua vez, a altura das plantas (AP) tende a ser menor com o aumento da população de plantas $\left(\mathrm{y}_{\mathrm{AP}}=74,829677419355\right.$ - 0,000109538065x $+0,00000000011 x^{2}$, $\left.\mathrm{R}^{2}=0,99\right)$, atingindo o menor valor $(47,56$ $\mathrm{cm}$ ) na densidade de 498 mil plantas ha-1. As observações efetuadas estão de acordo com Kanton et al. (2002), citado por Baier et al. (2009), os quais observaram redução na altura das plantas com o incremento da densidade de plantio. Em outras espécies, como o trigo e o feijoeiro, tal comportamento tem sido atribuído à redução do espaçamento entre linhas (Fontes et al., 2000; Horn et al., 2000), o que é coerente com os espaçamentos e
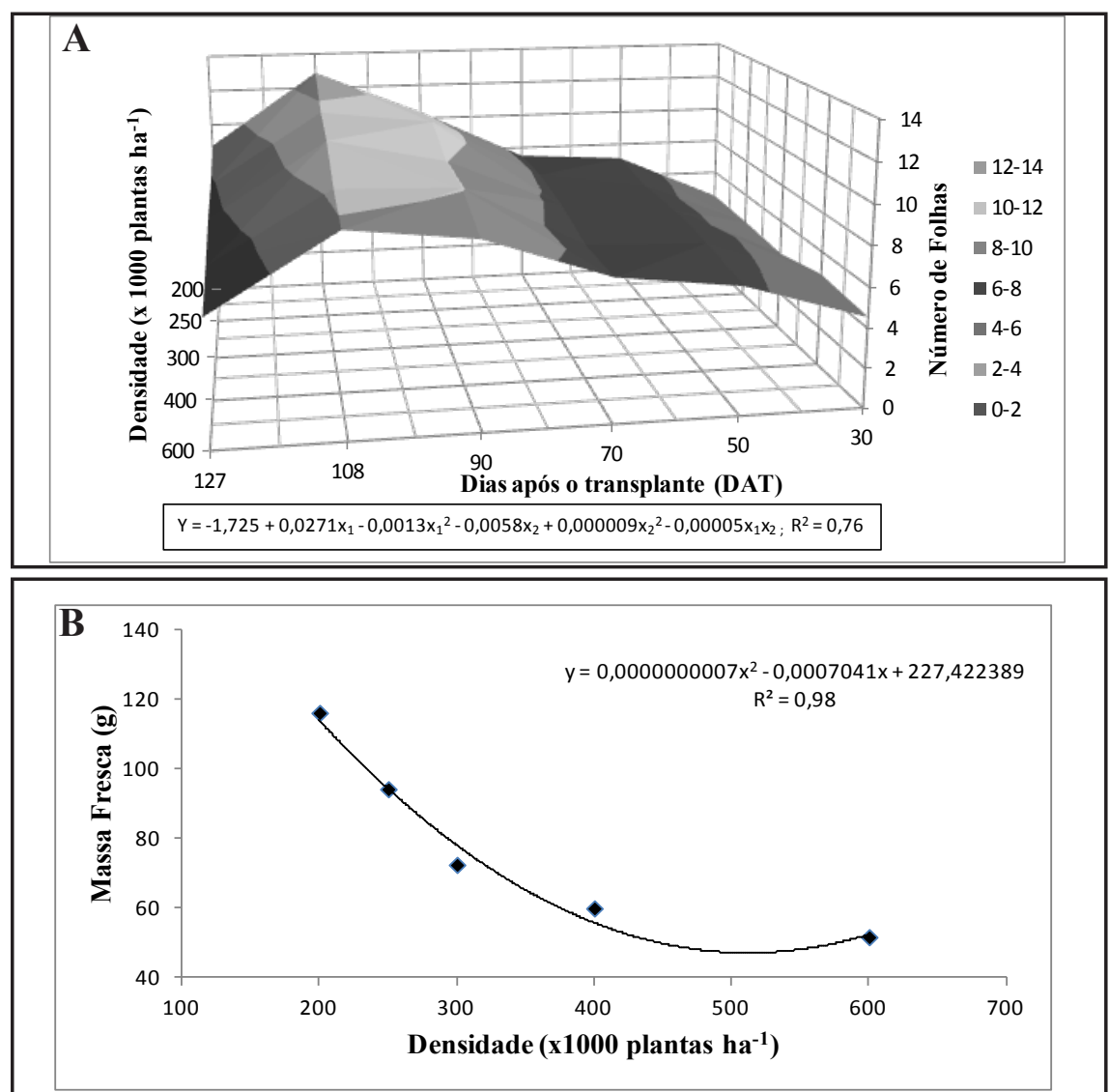

Figura 1. Número de folhas em função da interação densidades de plantio e dias após o transplante (A) e massa fresca dos bulbos em função de densidades de plantio (B) da cultivar Empasc 355-Juporanga [number of leaves depending on interaction of planting densities and dates of evaluation (A) and fresh mass of bulbs according to planting densities (B) of the cultivar Empasc 355-Juporanga]. Ituporanga, Epagri, 2010. 


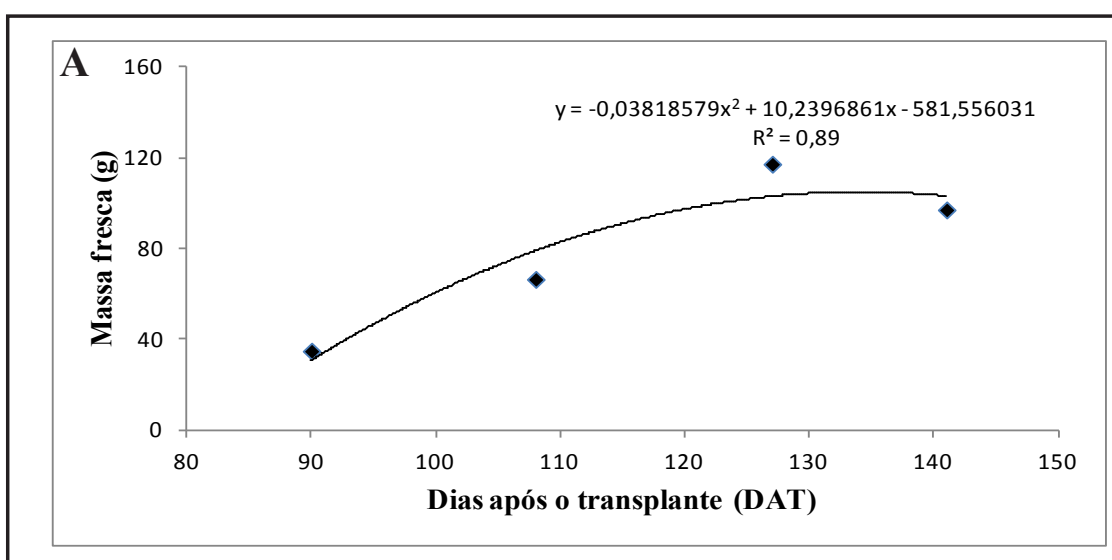

B

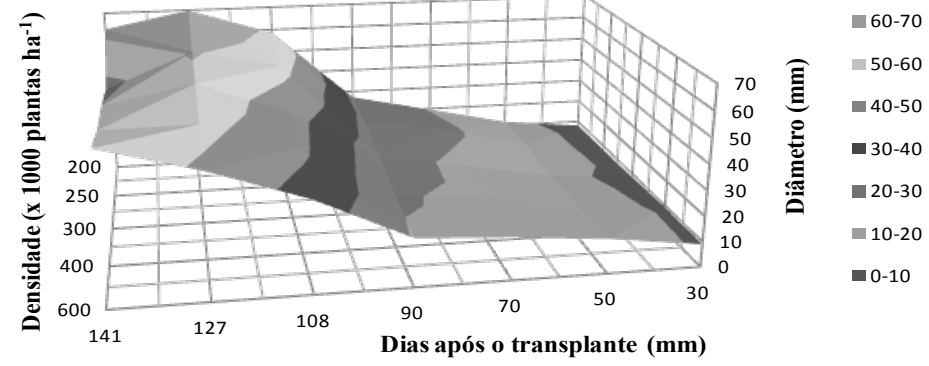

$y=10,09067166+0,27055588 x_{1}+0,00183267 x_{1}{ }^{2}-0,06682302 x_{2}+0,00009222 x_{2}{ }^{2}-0,00028109 x_{1} x_{2} ; R 2=0,90$

Figura 2. Massa fresca dos bulbos (MFB) em função de dias após o transplante (A) e diâmetro do bulbo (DB) em função da interação densidades de plantio e dias após o transplante (B) da cultivar Empasc 355-Juporanga [fresh weight of bulbs (MFB) depending on days after transplantation (A) and diameter of the bulbs (DB) depending on the interaction of planting densities and dates of evaluation (B) of the cultivar Empasc 355-Juporanga]. Ituporanga, Epagri, 2010.

disposições espaciais adotados no presente experimento para as maiores populações de plantas. Possivelmente, essas respostas estejam relacionadas à maior competição intraespecífica estabelecida por fatores de produção como água e nutrientes e redução do ciclo vegetativo, ocasionado pela menor distância entre linhas de plantas (Silva et al., 2009). Quanto ao número de folhas (NF), massa fresca da porção tubular das folhas (MFF) e massa seca da porção tubular das folhas (MSF), as interações existentes entre a população de plantas e os DAT (dias após o transplante) indicam que populações menores tendem a emitir um maior número de folhas e com isso atingir maiores MFF e MSF $\left(\mathrm{y}_{\mathrm{MFF}}=-495,24906663+13,07612451 \mathrm{x}_{1}\right.$ $-0,06397234 \mathrm{x}_{1}{ }^{2}-0,68399959 \mathrm{x}_{2}+$ $0,00043503 \mathrm{x}_{2}^{2}+0,00213136 \mathrm{x}_{1} \mathrm{x}_{2}, \mathrm{R}^{2}=$ 0,$79 ; \mathrm{y}_{\mathrm{MSF}}=-55,50106773+1,30686136 \mathrm{x}_{1}$ $-0,00618583 \mathrm{x}_{1}^{2}-0,04616832 \mathrm{x}_{2}+$
$0,00002868 \mathrm{x}_{2}^{2}+0,00014062 \mathrm{x}_{1} \mathrm{x}_{2}, \mathrm{R}^{2}$ $=0,88)$. $\mathrm{O}$ máximo número de folhas emitido nas populações de 200 e 300 mil plantas ha ${ }^{-1}$ ocorreu aproximadamente aos 108 DAT, enquanto que para 400 e 600 mil plantas ha-1 ocorreu aos 94 e 90 DAT, respectivamente. Isso pode indicar que plantas conduzidas sob maiores densidades populacionais reduzem seu ritmo de crescimento e desenvolvimento acelerando o ciclo cultural, assemelhando-se ao ocorrido com DP e AP (Figura 1A).

A máxima emissão de folhas e de acúmulo de massa fresca e seca do pseudocaule e das folhas, ocorrido aproximadamente aos 108 DAT, indica o fim do crescimento das folhas aéreas. Nesse período, considerando a média geral dos tratamentos, observou-se que aproximadamente $55 \%$ da massa final dos bulbos já haviam sido formadas.

De acordo com Oliveira (2011), a fase de desenvolvimento dos bulbos ocorre quando a planta suspende a formação de folhas, a taxa de crescimento das folhas decresce e as bainhas foliares do bulbo intumescem para formar o tecido de armazenamento. No entanto, pelo presente experimento, observa-se que a passagem para a fase de desenvolvimento dos bulbos não é tão nítida uma vez que o crescimento da planta ocorre concomitantemente ao processo de bulbificação.

$\mathrm{O}$ aumento da população de plantas reduziu a massa fresca média dos bulbos (MFB). Nas densidades empregadas para a cultivar Empasc 355-Juporanga, verificou-se que a menor MFB $(50,37 \mathrm{~g}$ bulbo $^{-1}$ ) foi obtida em população aproximada de 503 mil plantas ha ${ }^{-1}$, enquanto a maior MFB (114,60 $\left.\mathrm{g}^{\text {bulbo }}{ }^{-1}\right)$ foi observada em populações de 200 mil plantas ha $^{-1}$ (Figura 1B).

Santos et al. (2000), ao estudarem o efeito de espaçamentos entre plantas na linha também observaram que a redução no espaçamento é responsável pela redução na massa fresca do bulbo e aumento da produtividade. $\mathrm{O}$ aumento da produtividade total e a redução da massa fresca do bulbo oriundo do aumento da densidade de plantio também fora relatado por outros autores (Mohammedali, 1992; Brewster, 1994; Boff et al., 1998; Dellacecca \& Lovato, 2000; Resende et al., 2005; Baier et al., 2009).

Por sua vez, através da Figura 2A é possível observar que a máxima MFB $\left(104,90 \mathrm{~g} \mathrm{bulbo}^{-1}\right)$ foi obtida aos 134 DAT. Neste período, a taxa de crescimento diária foi de $1,68 \mathrm{~g} \mathrm{dia}^{-1}$, com tendência a diminuir a partir desse ponto (Figura 2A).

Observando a Figura 2B, nota-se que maiores densidades de plantio reduzem $\mathrm{o}$ DB. Verificou-se que as plantas submetidas a densidades de até 300 mil plantas ha ${ }^{-1}$ alcançam DB de 60 a 70 mm bulbo ${ }^{-1}$, enquanto que densidades acima daquele valor atingem no máximo valores de $50 \mathrm{a}$ $60 \mathrm{~mm}^{\text {bulbo }^{-1}}$ (Figura 2B). Ao utilizarem os híbridos Optima e Superex, May et al. (2007) obtiveram maior percentagem de bulbos, com diâmetro transversal entre 50 e $70 \mathrm{~mm}$, em densidade de $600 \mathrm{mil}$ plantas ha-1.

Nas menores densidades de plantio valores de $\mathrm{DB}$ iguais ou superiores a $50 \mathrm{~mm}$ (correspondentes a classe $3 \mathrm{e}$ 


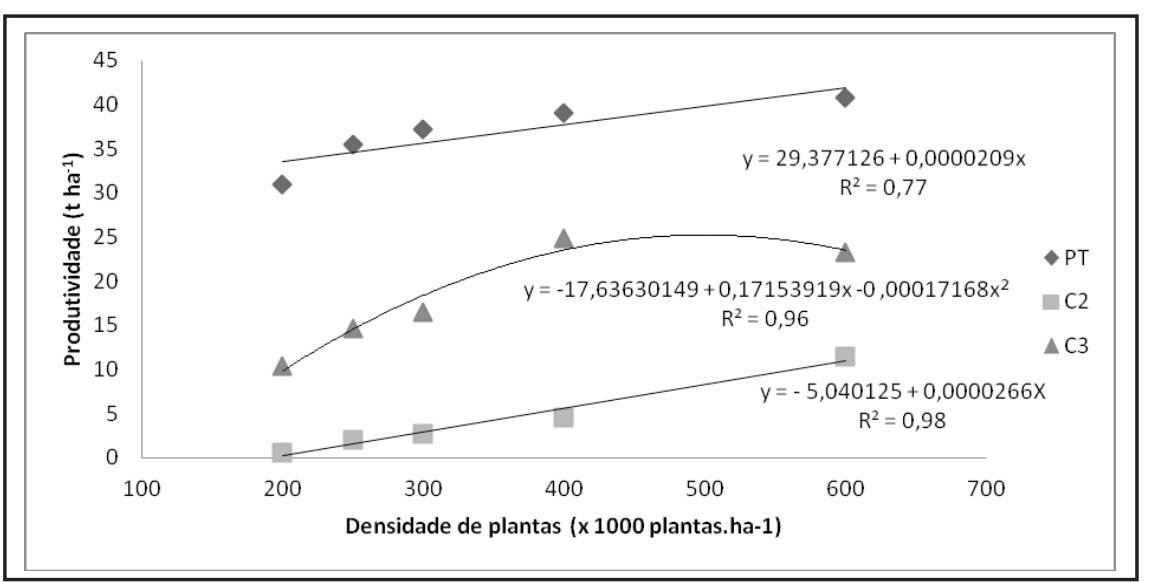

Figura 3. Produtividade total (PT), da classe 2 (C2) e da classe 3 (C3) da cultivar Empasc 355-Juporanga em função das densidades de plantio [total (PT), class 2 (C2) and class 3 (C3) productivities of the cultivar Empasc 355-Juporanga depending on planting densities]. Ituporanga, Epagri, 2010.

superiores) são obtidos num período de tempo inferior em relação às populações mais densas (Figura 2B). Assim, enquanto na menor densidade de plantio (200 mil plantas ha-1) as plantas atingem aqueles valores aproximadamente aos 116 DAT $\left(49,94 \mathrm{~mm}\right.$ bulbo $\left.^{-1}\right)$, na maior densidade de plantio $\left(600\right.$ mil plantas $\left.\mathrm{ha}^{-1}\right)$ esses diâmetros de bulbo só serão alcançados aos 134 DAT $\left(49,77 \mathrm{~mm}_{\text {bulbo }}{ }^{-1}\right)$.

No final do ciclo, a partir de aproximadamente 134 DAT, verifica-se a tendência de perda da MFB e diminuição do DB, a qual é mais acentuada nas maiores densidades de plantio (Figuras 2Ae 2B). Supõe-se que este comportamento esteja relacionado a perdas de massa fresca por desidratação e, em menor intensidade, ao processo respiratório, uma vez que as plantas foram mantidas no campo e colhidas quando apresentaram mais de $70 \%$ de tombamento. No caso das maiores densidades de plantio, tal fato também pode ser explicado pelos menores NF, MFF e MSF, em consequência da aceleração do ciclo cultural, devido à competição intraespecífica estabelecida. Estes resultados são concordantes com Almeida (2006) e Baier et al. (2009), segundo os quais, sob maiores densidades de plantio, as plantas aceleram o ciclo, a formação e maturação de bulbos.

Para todas as densidades de plantio, a colheita foi realizada na mesma data (141 DAT). Plantas conduzidas sob maiores densidades populacionais mostraram menor crescimento e aceleração do ciclo cultural, sendo responsável pela formação de bulbos com menor MFB e DB. De acordo com a Figura 2B, supõe-se que a realização da colheita entre 127 e 141 DAT seria mais adequada à obtenção de bulbos da classe 3. Poucas informações existem sobre o melhor período de colheita da cultivar, em especial sob diferentes densidades populacionais, havendo a necessidade de estudos que comprovem a hipótese anterior.

Por sua vez, o maior desenvolvimento vegetativo das plantas conduzidas em menores densidades populacionais e sua colheita tardia proporcionaram um aumento na produção de bulbos de diâmetro superiores à classe 3 . Resultado esse similar ao obtido por Wall \& Corgan (1994) ao realizar a colheita tardia de bulbos de cebola de cultivares de ciclo precoce. Nessa condição, o aumento de tamanho e peso dos bulbos ocorre devido a estes continuarem a receber fotossintatos das folhas fotossinteticamente ativas mesmo após $90 \%$ de tombamento das hastes (Davis \& Jones, 1963, citados por Miranda et al., 1996; Sargent et al., 2001). Considerando este aspecto e aceleração do ciclo de cultivo para densidades de plantio de 400 a 600 mil plantas ha ${ }^{-1}$, os bulbos poderiam ter sido colhidos a partir dos 135 DAT, cerca de uma semana antes da data em que foi realizada a colheita, o que provavelmente garantiria uma maior quantidade de bulbos da classe 3 .

Aos 108 DAT foram observados os maiores valores de massa fresca total (MFT) para todas as populações de plantas $\left(\mathrm{y}_{\mathrm{MFT}}=-20,81417205+3,45050044 \mathrm{x}_{1}\right.$ $-0,00702227 \mathrm{x}_{1}^{2}-0,44731352 \mathrm{x}_{2}+$
$0,00064603 \mathrm{x}_{2}^{2}-0,00244348 \mathrm{x}_{1} \mathrm{x}_{2}, \mathrm{R}=$ $0,79)$. Após esse período verifica-se a tendência de diminuição. Valores máximos de MFT são alcançados em menores densidades populacionais antes das plantas submetidas a maiores densidades populacionais, evidenciando um maior crescimento vegetativo das folhas revelado pela maior AP, NF e MFF registrados nesse período, justificando os maiores $\mathrm{DB}$ e MFB observados para as plantas no final do ciclo produtivo.

O maior desenvolvimento e crescimento da porção tubular das folhas no período de 108 DAT, obtido para densidades de plantio menores, provavelmente ao garantir o processo fotossintético, possibilitaram um maior acúmulo e translocação de carboidratos por ocasião do período de bulbificação. Por sua vez, quanto maior o número de folhas maior a possibilidade de obtenção de bulbos de maior diâmetro e ganho de massa fresca e seca, uma vez que o NF está intimamente relacionado ao número de bainhas foliares. De acordo com FARUQ et al. (2003), quanto maior a atividade fotossintética da planta, seja através do maior número de folhas da planta ou crescimento vegetativo mais vigoroso, maior é o acúmulo de fotossintatos, afetando a produção de bulbos.

Quanto à massa seca dos bulbos (MSB), observou-se que nas menores densidades de plantio as MSB alcançam valores acima de 9 g planta $^{-1}$ antes das maiores densidades, atingindo valores máximos aos 127 DAT $\left(\mathrm{y}_{\mathrm{MSB}}=-52,78199701+1,02547606 \mathrm{x}_{1}\right.$ $-0,00340984 \mathrm{x}_{1}{ }^{2}-0,02661415 \mathrm{x}_{2}+$ $0,00004790 x_{2}^{2}-0,00021655_{1} x_{2} ; R^{2}=$ $0,79)$. Posterior a essa data verifica-se a tendência de diminuição da MSB. Estes podem ser indicativos de que as plantas após 127 DAT param de acumular compostos carbônicos e já têm definido o número de células nas bainhas foliares e que deste período em diante até aos 134 DAT (momento da máxima MFB) os ganhos em massa fresca devem-se ao predomínio do processo de expansão celular sobre o processo de divisão celular. A massa seca total (MST) seguiu a mesma tendência da MSB, devido à maior contribuição em termos de massa seca ser dos bulbos $\left(\mathrm{y}_{\mathrm{MST}}=-3,05669434+0,26310444 \mathrm{x}_{1}\right.$ $-0,000024840 \mathrm{x}_{1}{ }^{2}-0,02729276 \mathrm{x}_{2}+$ $0,00004481 x_{2}^{2}-0,00023284 x_{1} x_{2}, R^{2}=$ 
$0,79)$.

Os dados de produtividade indicam que não houve diferenças significativas $(p>0,05)$ entre as densidades populacionais utilizadas paras as produtividades comercial (PC) e da classe 3 e superiores $(\mathrm{C} 3+)$, as quais em média foram de 36,19 e 31,91 t ha-1, respectivamente. Por sua vez, a produtividade total de bulbos (PT) e de bulbos da classe 2 (C2) aumentaram linearmente com o aumento da densidade populacional de plantas (Figura 3). Portanto, ao se elevar a densidade de plantio há um aumento da produtividade total, porém com a formação de um maior número de bulbos de menor massa fresca e diâmetro transversal. Esses resultados concordam com outros autores, os quais observaram as mesmas tendências ao aumentar a densidade populacional de suas lavouras (Brewster, 1994; Stoffella, 1996, Santos et al., 2000; Dellacecca \& Lovato, 2000).

Em estudo de caracterização da cultivar Empasc 355-Juporanga, Gandin et al. (1994) observaram produtividade de 33,38 t ha-1 em população de 333.333 plantas $\mathrm{ha}^{-1}$. No presente ensaio, os dados de produtividade aos 141 DAT mostram que a produtividade comercial média (dados observados), considerando a média geral dos tratamentos (populações de plantas), foi de $36,19 \mathrm{t} \mathrm{ha}^{-1}$.

Por sua vez, ao analisarmos a obtenção de bulbos considerados de melhor qualidade, os dados revelam que a máxima produtividade de bulbos da classe $3(25,21$ t ha ${ }^{-1}$ ) é obtida com uma população de 499.590 plantas ha $^{-1}$ (Figura 3).

Não houve diferenças significativas $(\mathrm{p}>0,05)$, entre as densidades de plantio, para a perda de massa de bulbos após três meses de armazenamento, a qual em media foi de $54 \%$. Isso indica que independente da população de plantas adotada o comportamento da perda de massa de bulbo na pós-colheita não se alterou.

$\mathrm{Na}$ região do Alto Vale do Itajaí têm sido comumente recomendadas populações de 333 mil plantas ha ${ }^{-1}$. O custo médio de mão de obra para o estabelecimento desta população e sua colheita, considerando as cinco últimas safras agrícolas de 2006 a 2010, é de R \$ 1.850,00, representando 30\% do custo de produção da cultura. No mesmo período, o preço médio pago ao produtor por quilo do produto foi de $\mathrm{R} \$ 0,61$ para bulbos da classe 3 e superiores.

$\mathrm{O}$ aumento da densidade de plantio de 333 mil para 600 mil plantas ha h $^{-1}$, representa uma elevação de $80 \%$ no custo de mão de obra (de R $\$ 1.850,00$ para R\$ 3.330,00). Além disso, bulbos de classe 2 recebem no mercado da região do Alto Vale do Itajaí metade do preço ao produtor praticado em classes superiores. Nesse sentido, seria de esperar que populações mais densas sejam antieconômicas. No entanto, considerando a ausência de diferenças para as densidades de plantio para a produtividade de bulbos da classe 3 e superiores, a produção média de 31,91 t ha-1 (valor observado) representa um valor pago ao produtor de $\mathrm{R} \$ 19.465,10$. A esse valor devem ser somados os ganhos adicionais oriundos da produção de bulbos da classe 2 .

No caso de uma população de 333 mil plantas ha-1 teremos um acréscimo de $3,83 \mathrm{t} \mathrm{ha}^{-1}$ ( $\left.\mathrm{R} \$ 1.168,15\right)$, enquanto para uma densidade de plantio de 600 mil plantas ha-1 este será de $10,92 \mathrm{t} \mathrm{ha}^{-1}$ (R\$ 3.330,60). Tendo em vista que a única alteração realizada no sistema de produção foi o aumento da densidade de plantas e a correspondente elevação no custo de mão de obra do cultivo relativo às operações de plantio e colheita, ao se descontar os valores de receita dos custos de produção verificam-se para uma população de 333 e 600 mil plantas $\mathrm{ha}^{-1}$, receitas brutas de $\mathrm{R} \$ 18.783,25 \mathrm{e}$ R\$ 19.465,70, respectivamente.

Portanto, a análise custo/benefício revela que ao se aumentar a população de plantas de 333 para 600 mil plantas $\mathrm{ha}^{-1}$ os ganhos obtidos em produtividade oriundos da adição de bulbos classe 2 compensam os maiores custos de produção com mão-de-obra relativos ao transplante e colheita e aumentam a rentabilidade da cultura ao produtor.

Nas condições experimentais do presente experimento, conclui-se que o aumento da população de plantas não influenciou a conservação de bulbos na pós-colheita após três meses de armazenamento, porém acelerou o ciclo da cultivar Empasc 355-Juporanga, reduziu o diâmetro e massa fresca dos bulbos e aumentou a produtividade total e de bulbos da classe 2 (C2). A ausência de diferenças significativas na produção comercial (PC) e de bulbos da classe 3 e superiores $(\mathrm{C} 3+)$, a produtividade de bulbos da classe 3 (C3) e os custos do sistema de produção indicam maior rentabilidade com o uso de densidades populacionais entre 400 e $600 \mathrm{mil}$ plantas ha-1.

\section{REFERÊNCIAS}

ALMEIDA D. 2006. Manual de Culturas Hortícolas. Volume I. Barcarena: Editorial Presença. 360p.

BAIER JE; RESENDE JTV; GALVÃO AG; BATTISTELLI GM; MACHADO MM; FARIA MV. 2009. Produtividade e rendimento comercial de bulbos de cebola em função da densidade de cultivo. Ciência \& Agrotecnologia 33: 496-501.

BOFF P; HENRI S; GONCCALVES PAS. 1998. Influência da densidade de plantas na ocorrência de doenças foliares e produção de bulbos de cebola. Fitopatologia Brasileira 23: 448-452.

BRASIL. 1995. Ministério da Agricultura, Abastecimento e Reforma Agrária. Portaria n.529 de 18 ago. 1995. Diário Oficial da República Federativa do Brasil. Brasília, 1 de set. 1995, Seção 1: 13513.

BREWSTER JL. 1994. Onion and other vegetable alliums. Wallingford: CAB Internacional. 236p.

CECÍLIO FILHO AB; MAY A; PÔRTO DRQ; STEIN RC; VARGAS PF. 2006. Produtividade e qualidade de bulbos de duas cultivares de cebola em função da população de plantas, em semeadura direta. Revista Caatinga 19: 146-152.

COMISSÃO DE QUÍMICA E FERTILIDADE DO SOLO RS/SC - CQFS-RS/SC. 2004. Manual de adubação e de calagem para o Estado do Rio Grande do Sul e Santa Catarina. Porto Alegre: UFRGS. 400p.

DELLACECCA V; LOVATO AFS. 2000. Effects of different plant densities and planting systems on onion (Allium cepa L.) Bulb quality and yield. Acta Horticulturae. (ISHS) 533: 197-204. Disponível em http://www.actahort. org/books/533/533 24.htm. Acessado em 20 de março de 2011.

EMBRAPA. 1997. Centro Nacional de Pesquisa Tecnológica em Informática para a Agricultura. Ambiente de software NTIA, versão 4.2.2: manual do usuário - ferramental estatístico. Campinas: EMBRAPA/CNPTIA. 258p.

EPAGRI. 2000. Sistemas de produção para cebola para o estado de Santa Catarina. Florianópolis: Epagri. 91p. (Sistemas de Produção n.16).

FARUQ MO; ALAM MS; RAHMAN M; SHARFUDDIN AFM. 2003. Growth, yield and storage performance of onion as influenced by planting time and storage condition. Pakistan Journal of Biological Sciences 6: 1179-1182.

FERREIRA MD. 2000. Cultura da cebola: 
recomendações técnicas. Campinas: ASGROW. 36p.

FONTES JRM; CARDOSO AA; SOUZA MA; CRUZ CD. 2000. Relação do espaçamento e da densidade de semeadura com o rendimento de grãos e outras características agronômicas do trigo. Revista Ceres 47: 61-73.

GALMARINI CR; GASPERA PG. 1995. Efecto de la epoca de transplantey la densidad de plantacion en el cultivo de cebolla tipo Valenciana. Horticultura Argentina 4:23-29.

GANDIN CL; YOKOYAMA S; THOMAZELLI LF; GUIMARÃES DR; BIASI J; BECKER WF; FAORO ID; NETO JAZ; PIANA Z; MÜLLER JJV; SILVA ACF; VIZZOTTO VJ. 1989. Nova cultivar de cebola de ciclo médio para SC. Agropecuária Catarinense 2: 40-42.

GANDIN CL; GUIMARÃES DR; THOMAZELLI LF. 1994. Caracterização de quatro cultivares de cebola lançadas em Santa Catarina, Brasil. Pesquisa Agropecuária Brasileira 29: 19411945.

HORN FL; SCHUCH LOB, SILVEIRA EP; ANTUNES IF; VIEIRA JC; MARCHIORO G; MEDEIROS DF; SCHWENGBER JE. 2000. Avaliação de espaçamentos e populações de plantas de feijão visando à colheita mecanizada direta. Pesquisa Agropecuária Brasileira 35: 41-46.

LOPES JF. 1987. Effects of planting dates and spacing on several characteristics of short day onion varieties grown in South Texas. College Station : College of Texas A \& M University. 111p. (Tese PhD).

MAY A; CECÍLIO FILHO AB; PORTO DRQ; VARGAS PF; BARBOSA JC. 2007. Efeitos de doses de nitrogênio e potássio e densidade populacional sobre a classificação de bulbos de cebola. Horticultura Brasileira 25: 396-401.

MELO PCT; RIBEIRO A; CHURATA MASCA MGC. 1988. Sistemas de produção, cultivares de cebola e seu desenvolvimento para as condições brasileiras. In: SEMINÁRIO NACIONAL DE CEBOLA. Anais... Jaboticabal: FUNEP. p. 27-61.

MIRANDA MN; BILHALVA AB; SILVEIRA JÚNIOR P. 1996. Efeito da época de colheita e armazenamento na conservação de cebola (Allium cepa L.), cv. Petrolini. Revista Brasileira de Agrociência 2: 155-158.

MOHAMMEDALI GH. 1992. Effect of plant population densities on yield and quality of white dehydration onion in the northern Sudan. Emirates Journal of Food and Agriculture 4: 213-219.

OLIVEIRAVR. 2011. O cultivo da cebola. Disponível em: http://www.unitins.br/ates/arquivos/ Agricultura/Olericultura/Cebola/Cebola\%20 -20Cultivo.pdf.Acesso em: 15 de março de 2011.

RABINOWITCH HD; BREWSTER JL. 1990. Onion and allied crops. Boca Raton: CRC Press. 273p.
RESENDE GM; COSTAND; ALVARENGAMAR. 2005. Rendimento e perda de peso de bulbos de cebola cv. Texas Grano 502 PPR em diferentes espaçamentos de plantio. Caatinga 18: 28-34.

SANTOS HS; TANAKA MT; WATANABE SH; ARANTES PAZ; IVONE TT. 2000. Produção de cebola em função de tamanho de muda e espaçamento. Horticultura Brasileira.18: 556557. Suplemento.

SARGENT SA; STOFFELLA PJ; MAYNARD DN. 2001. Harvest date affects yield and postharvest quality of nondried short-day onions. Hortscience 36: 112-115.

SILVAAG; MORAES EB; PIRES R; CARVALHO CGP; OLIVEIRA ACB. 2009. Efeitos do espaçamento entre linhas nos caracteres agronômicos de três híbridos de girassol cultivados na safrinha. Pesquisa Agropecuária Tropical. 39: 105-110.

STOFFELLA PJ. 1996. Planting arrangement and density of transplants influence sweet spanish onion yields and bulbs size. Hortscience 31: 1129-1130.

WALL MM; CORGAN JN. 1994. Postharvest losses from delayed harvest and during common storage of short-day onions. HortScience 29: 802-804.

ZONTA EP; MACHADO AA. 1984. SANEST - Sistema de Análise Estatística para Microcomputadores. Pelotas: UFPel. 75 p. 